\title{
Reproductive and hormonal risk factors of breast cancer: a historical perspective
}

\author{
This article was published in the following Dove Press journal: \\ International Journal of Women's Health \\ 27 April 2017 \\ Number of times this article has been viewed
}

\begin{abstract}
Julie Horn ${ }^{1,2}$
Lars J Vatten'

'Department of Public Health and Nursing, Faculty of Medicine and Health Sciences, Norwegian University of Science and Technology, Trondheim, Norway; ${ }^{2}$ Department of Gynecology and Obstetrics, Levanger Hospital, Nord-Trøndelag Hospital

Trust, Levanger, Norway
\end{abstract}

\begin{abstract}
The complexity of breast cancer etiology has puzzled scientists for more than 300 years. In this brief review, we emphasize the importance of reproductive and hormonal factors in relation to the risk of breast cancer. By following the historical course of how various risk factors have been determined, this study attempts to illustrate the origin of hypotheses, their subsequent rejection, and development of new hypotheses. Starting with the contributions of Italian physicians in the 18th century and covering the activity of British epidemiologists before World War II, this review ends up with the international collaboration that became increasingly important in the second half of the 20th century.
\end{abstract}

Keywords: age at first birth, epidemiology, estrogen, lactation, parity, pregnancy

\section{Introduction}

A quotation from Hubert Campbell still seems to be as relevant now as it was in 1971: "Breast cancer is an endemic disease which has been investigated for two hundred years, and the one clear factor about the etiology is its complexity." This review demonstrates this complexity by following the historical course of presently established risk factors of breast cancer, with special emphasis on reproductive and hormonal factors. We wanted to elucidate how scientists from various scientific fields have interacted, how their research hypotheses arose, and how unexpected findings directed research into new directions. The historical perspective may deepen our understanding of current risk factors and illustrate that scientific investigation is not necessarily a linear process. A broad impression of scientific development may only emerge from a temporal distance, and therefore, our review focused on the research of breast cancer risk factors from the 18th century until the 20th century.

\section{The I 8th and I9th centuries: early clues in the importance of reproductive factors}

Intuitively one would not expect knowledge of breast cancer risk factors to originate from occupational medicine, but the first hint that nulliparity may increase the risk of breast cancer emerged more than 300 years ago, in a famous book by the father of occupational medicine, Bernadino Ramazzini (1633-1714). ${ }^{2}$ During the period dominated by Galen's medical theories, Ramazzini emphasized working conditions and suggested that every initial consultation should include occupational history. ${ }^{2}$

In his book, De Morbis Artificum Diatriba (Diseases of Workers), Ramazzini describes the working conditions and human health for $\sim 50$ different occupations. One chapter, entitled "Diseases of wet-nurses," is devoted to the relationship between the uterus and the breasts or - to use Ramazzini's expression: "this marvelous sympathy
Correspondence: Julie Horn

Department of Public Health and Nursing, Faculty of Medicine and Health Sciences, Norwegian University of Science and Technology, Håkon Jarls gate II, N-7489 Trondheim, Norway

Tel +47 74075 I 85

Email julie.horn@ntnu.no 
of the breasts and uterus, those two sources of desire." 3 He describes the high frequency of breast cancer in nuns compared with other women and speculates that their celibate life could be an important cause of the higher risk in nuns. Although Ramazzini makes no direct connection between a lack of sexual activity and childbearing, his words are often seen as the first hint of an association between reproduction, parity, and risk of breast cancer. ${ }^{4}$

Ramazzini's writing style was polemic, and to readers who might disagree with his theories, he had the following request: "cui opinioni qui non acquiescit, meliora proferat"; "anyone who does not accept this view should produce something better". Nonetheless, he realized that much remained to be discovered:

This century, however, is hastening to its finish, and we may assume that it will not be granted the solution of this problem which the Supreme Disposer of all things has perhaps willed to reserve for some other century that is to follow.

Indeed, it took some time, but in 1842, the Italian surgeon Domenico Rigoni-Stern (1810-1855) used death registers in the Verona region to compare mortality of uterine and breast cancer between married and unmarried women. ${ }^{5,6}$ He confirmed that nuns had higher breast cancer mortality than married women, but he also found that nuns and other unmarried women had a lower risk of dying from uterine cancer. Although the classification of uterine cancer did not yet distinguish between diseases of the cervix and the corpus, and despite some criticism related to his methods, Rigoni-Stern's observation is considered the first clue that infection is a cause of cervical cancer. ${ }^{7,8}$

Like Ramazzini, before him, Rigoni-Stern had his thoughts about the risk in nuns, and consistent with the widespread opinion that chronic irritation may cause cancer, he suggested that tight corsets or long-lasting praying positions could be an important factor. He had also observed that the four men registered with breast cancer were all priests. ${ }^{6}$ Although the latter has not been confirmed by others, a higher risk of breast cancer in nuns has been repeatedly verified. ${ }^{9-11}$

\section{Late 19th century: first clues in the importance of hormonal factors}

When Ramazzini wrote about the "wonderful sympathy and reciprocity between the breasts and the uterus", he speculated that the growing uterus supported by fetal movements would mechanically induce milk production. ${ }^{3}$ At the end of the 19th century, the British surgeon George Beatson acknowledged the possible link between lactation, ovarian function, and breast cancer. While spending time at an estate in Scotland in 1876, he was inspired by the weaning of the lambs and chose lactation as the topic for his thesis. ${ }^{12}$ Beatson wrote that the epithelial proliferation in a lactating mammary gland resembled the proliferation of breast cancer cells and postulated that proliferating cells undergo fatty degeneration during lactation, whereas this process could be interrupted in cancerous cells: "In short, lactation is at one point perilously near becoming a cancerous process if it is at all arrested". Local farmers had taught him that eliminating a cow's ovarian function would prolong lactation. Bearing that in mind, he thought that removing the ovaries of breast cancer patients might induce fatty degeneration and stop cancerous growth. After graduation, Beatson worked as a house surgeon of Joseph Lister, the father of antiseptic surgery, and later he became a surgeon at the Glasgow Cancer Hospital. ${ }^{13}$ In 1895 , he removed both the ovaries of a young mother with advanced breast cancer, after which the tumor regressed. ${ }^{12}$ Other surgeons adopted Beatson's approach, and oophorectomy formed the beginning of antihormonal therapy of breast cancer.

Beatson had searched in vain for a special nerve that could control lactation, and he described the relationship between the breast and the ovaries as "one organ holding the control over the secretion of another and separate organ." Although he was close to understanding the concept of hormonal activity, the word hormone was first coined several years later, in 1905, by the British physiologist Ernest Starling. ${ }^{14}$

Between 1915 and 1920, the American pathologist Leo Loeb published a series of reports on the origin of tumors in mice. ${ }^{15}$ His research did not support the popular hypothesis that infections caused cancer, but he found evidence to support hereditary factors. ${ }^{16}$ However, his contribution to the understanding of ovarian hormones both for the mammary gland and for breast cancer development was probably more important: "Our results enable us to conclude that in all probability the ovarian hormone and not the effect of pregnancy and nursing is directly responsible for the difference in the cancer rate in male and female mice". He reported that pregnancy stimulated the growth of mammary tumors, whereas castration prevented mammary tumors in mice to occur. ${ }^{17}$

\section{Interwar period: growing public health interest in the development of breast cancer}

However, after the League of Nations was established shortly after World War I, aspects of public health came into focus. 
The newly appointed Health Committee provided a basis for international cooperation, and in 1923, a Sub-Committee on Cancer was installed, which supported etiologic and therapeutic studies on cancer. ${ }^{18-20}$ Thereafter, national cancer committees were established, including the Departmental Committee on Cancer appointed by the British Ministry of Health. ${ }^{19,21}$ Cancer of the female breast and genital organs attracted much research interest, maybe partly due to easier detectability of these organs, but probably also because the frequency of cancer was generally higher in women than in men; in fact, cancer was considered a predominantly female disease. ${ }^{18,22}$ Also, comparative studies of breast cancer mortality between Holland, Italy, and England disclosed considerable differences between the countries, and the SubCommittee on Cancer encouraged national investigations of antecedent factors. ${ }^{23}$

Major Greenwood, a member of the British Departmental Committee on Cancer and later first professor of medical statistics at the London School of Hygiene and Tropical Medicine, appointed a former colleague, Janet Lane-Claypon, to perform these investigations. ${ }^{24}$ Lane-Claypon was a physiologist and medical doctor who had already executed highly regarding epidemiological studies on hygiene and children's health. In the following years, she contributed substantially to the understanding of factors that influence the occurrence of breast cancer. Her name also remains associated with important methodological contributions to epidemiologic research; she conducted the first case-control study as well as the first retrospective cohort study. ${ }^{25,26}$ Lane-Claypon's best-known publication was published in 1926 and is entitled "A Further Report on Cancer of the Breast with special reference to its associated antecedent conditions." 27 Using a case-control design, she compared 500 breast cancer patients (cases) and 500 other hospital patients (controls) recruited from hospitals in London and Glasgow. The results suggested that women with low parity, women who married relatively late (a proxy for age at first birth), and women who had not breastfed were at higher risk of breast cancer than other women. In her conclusion, she states: "The breast which has never been called upon for normal function is certainly more liable to become cancerous".

Besides reproductive factors, Lane-Claypon also examined the family history and local irritation and injury, both of which were subjects of controversial discussions at the beginning of the 20th century. ${ }^{28}$ The hereditary hypothesis was met with skepticism, whereas local injury and irritation were widely accepted as causes of cancer. ${ }^{22,28}$ Lane-Claypon found a weak but positive association of familial factors, based on the medical histories of parents and grandparents of her study participants. She also found that previous breast problems related to lactation, deformations, or injury were more common among breast cancer cases compared with controls. Discussing her results, however, she considered the possibility that recall bias might explain the latter findings. Contrary to expectations, she found no association of puerperal mastitis. Breastfeeding - and puerperal mastitis had been suspected to contribute to the development of breast cancer through local irritation of the breast, and her observation that lack of breastfeeding was associated with higher breast cancer risk was somehow unexpected.

In 1931, Wainwright conducted a comparable study in the United States. ${ }^{29}$ His results also concluded that low parity, late age at marriage, and lack of breastfeeding were positively associated with risk for breast cancer. In a reanalysis of both studies in 2010, it was found that late menopause (both studies) and early age at menarche (Wainwright's study) were also associated with increased risk. ${ }^{30}$ Wainwright also examined whether foreign-born women could be more prone to breast cancer than women born in the United States. ${ }^{23}$ However, his results could not confirm that possibility, and his initial concern was refuted: "It is indicated that our foreign blood does not increase the tendency to cancer."

Janet Lane-Claypon continued to study cancer until her marriage in 1929, when she had to end her research career due to employment restrictions for married women. ${ }^{26}$ In one of her last joint publications with Major Greenwood, they put forward the following requirements for researchers in epidemiology:

It may not need much apparatus but it does require a great deal of patience, a healthy scepticism and a good deal of common sense, the last a quality not always conspicuous in the works of our young researchers. ${ }^{31}$

\section{After the war period Further evidence for the connection between hormones and development of breast cancer}

Major Greenwood probably gave the same advice to his mentee, Austin Bradford Hill, who subsequently may have passed it on to his young colleague, Richard Doll. ${ }^{32}$ Doll went into epidemiology shortly after World War II, and these two researchers became famous for their studies related to smoking and risk of lung cancer. Together with Peter Armitage, Doll published a landmark paper in 1954, where they propose a multistage model of carcinogenesis, 
hypothesizing that cancer is induced by a series of multiple mutations within a single cell. ${ }^{33,34}$ The basis for their hypothesis was the observed linear relationship between the logarithm of age and the logarithm of death rates due to cancer. Along with a number of other cancers, breast cancer deviated from that linear relationship, and Armitage and Doll concluded that carcinogenic factors for these cancers were not constant over time, which also complied with the suspected hormonal influence on the development of breast cancer.

The particular shape of the incidence curve of breast cancer had already been described by Johannes Clemmesen, the founder of the Danish Cancer Registry. In 1948, he wrote that the shape of the incidence curve of age indicated that the incidence slowed down around the age of menopause:

It would not seem unreasonable to connect this irregularity

with climacterial phenomena but at the moment no final

explanation can be given. ${ }^{35}$

The point of incidence change approximately coinciding with age at menopause has later been called Clemmesen's hook.

\section{The growing impact of exogenous hormones on the development of breast cancer}

However, in parallel with the awakening understanding of the relationship between hormones and development of breast cancer, exogenous hormones emerged as new risk factors. The first synthesized estrogen, diethylstilbestrol (DES), was discovered in 1938 and was enthusiastically received, especially by doctors who used the drug to alleviate postmenopausal symptoms, to treat gynecologic bleeding disorders, and as palliative treatment for advanced prostate cancer. ${ }^{36}$ Gynecologists also prescribed DES to prevent pregnancy complications such as preeclampsia, premature delivery, abortion, and intrauterine death. ${ }^{37}$

In the 1950 s, the synthesis of orally active progesterone lead to the development of combined oral contraception, and Enovid $^{\circledR}$, the first hormonal birth control pill, was approved for the treatment of menstrual disorders in the United States and Britain in 1957. Three years later, it was also approved as a contraceptive. Very soon, hormonal birth control became tremendously popular, and $>100$ million women are current users of combined contraception, with higher prevalence in developed compared with developing coutries. ${ }^{38,39}$

The use of sexual hormones as menopausal hormone therapy has become equally important. For a long time, menopause had been connected with a large number of physical and psychological problems in women. As early as in 1886, the British gynecologist and pioneer in pelvic surgery, Robert Lawson Tait, wrote in his famous textbook, Diseases of Women:

Very few women pass the climacteric period without more or less suffering, and in some cases permanent damage is encountered. The nervous symptoms may be so severe as to result in mental derangement, and this often takes the form of incurable dementia. ${ }^{40}$

However, his suggested treatment was rather limited:

For the relief of nearly all the subjective symptoms of the climacteric period, I know nothing better than the use of an occasional drastic purgative, and removal from home at frequent intervals. ${ }^{41}$

Isolation of estrogen from urine opened new treatment options, and oral hormonal therapy with conjugated estrogens became available from the 1940s. The brand of one such drug, Premarin, did not attempt to hide its origin: pregnant mare urine. In the 1960s, the benefits of estrogen replacement therapy were reinforced by the American gynecologist Robert Wilson, who wrote the following: "The unpalatable truth must be faced that all postmenopausal women are castrates. There is a variation in degree but not in fact." ${ }^{\prime 2}$ Wilson further prophesied,

The untold misery of alcoholism, drug addiction, divorce and broken homes caused by these unstable, estrogenstarved women cannot be presented in statistical form.

Only estrogen supply "from puberty to the grave" could save women from this destiny, and he even suggested a possible protective effect of estrogen and progesterone against breast and genital cancer. ${ }^{42,43}$ His best-selling book Feminine Forever was published in 1966, and Wilson compared intake of menopausal estrogen with insulin treatment for diabetes and promised women who took estrogens for everlasting youth and femininity. ${ }^{44}$ The sale of hormonal therapy increased steadily, and in 2000, approximately one in two American women between the ages of 50 and 65 years used menopausal hormonal therapy. ${ }^{39}$

Nonetheless, the success story of hormonal treatment was gradually counteracted by the growing awareness of its adverse effects. This coincided with the concerns about other drugs, especially thalidomide. In addition, DES had shown no beneficial effects on pregnancy complications, and the results of a case-control study published in 1971 suggested 
that vaginal cancer was more frequent in daughters of women who had been treated with DES in pregnancy. ${ }^{36}$ Subsequent studies in the 1980s until the early 2000s suggested that DES may increase the risk of breast cancer both in women who took DES in pregnancy and in their daughters who were exposed to DES in utero. ${ }^{45,46}$

In relation to the pill, early concerns were raised about the possibility of thromboembolic complications, and in the 1970s, the increasing incidence of breast and endometrial cancer attracted the interest of researchers who thought that using the pill might influence cancer risk. Research did not provide clear evidence, but in certain subgroups, especially women who reported long-term use before first pregnancy, there was some indication for increased risk. ${ }^{47,48}$ In later studies and subsequent meta-analyses, there was a small increase in risk associated with the current use of oral contraceptives. After cessation of use, the risk persisted but gradually subsided, and $\sim 10$ years after cessation, the risk was back to the expected level corresponding to the woman's age. . $^{39,49}$

The initial enthusiasm for menopausal estrogen treatment dampened in the 1970s after some studies had suggested that estrogen use may be associated with increased risk for endometrial cancer. ${ }^{50}$ The proposed solution to the problem was to restrict estrogen therapy to hysterectomized women, and to offer other women estrogens with an additional progestin component.

Over the years, indications for hormonal treatment were extended beyond alleviation of menopausal hot flushes or night sweats. The main reason was that results from observational studies suggested that hormonal treatment may prevent coronary heart disease and osteoporosis. ${ }^{51}$ On the other hand, there had been concerns that hormonal therapy may increase the risk of breast cancer, but results have not been consistent. ${ }^{52,53}$ The Women's Health Initiative was launched in 1992, and this randomized controlled trial was expected to solve the most important controversies related to the use of hormones during menopause. ${ }^{51}$ In 2002, the combined hormonal arm (estrogen and progestin) of the trial was stopped because of increased risk of coronary heart disease, stroke, and breast cancer. ${ }^{54}$ In the estrogen arm, there was no evidence for any association with the risk of breast cancer; however, that arm was stopped in 2004 due to increased risk of stroke. As a consequence of the Women's Health Initiative, the attitude toward hormonal therapy in postmenopausal women has completely changed. The term hormonal replacement is less used, and now, menopausal hormone therapy is the preferred term, reflecting that the primary goal is the relief of menopausal symptoms and that the postmenopausal period should no longer be regarded as a hormone deficiency disease.

\section{Understanding the dual effect of pregnancy on the risk of breast cancer}

Understanding the role of reproductive factors was not always straightforward. After World War II, national differences in the incidence of breast cancer continued to stimulate international collaboration. It was demonstrated that regions with different breast cancer rates also differed in breastfeeding patterns. While lactation was frequent and prolonged in Asia, where breast cancer was rare, breastfeeding was less common in the United States and Northern Europe, where the rates were high. ${ }^{55}$ In the early 1960s, Brian MacMahon initiated an international collaboration that included $>17,000$ women from regions with high (USA and UK), intermediate (Greece, Slovenia, and Brazil), and low incidence of breast cancer (Japan and Taiwan). ${ }^{56}$ The results of the study were published in 1970 and questioned the prevailing view on lactation and parity in relation to the risk of breast cancer. Contrary to expectations, no association of lactation with breast cancer was found, and there was no evidence that breastfeeding patterns could explain the differences in incidence of breast cancer between countries. ${ }^{56}$ Shortly afterward, in a paper that MacMahon considered retrospectively his most influential, ${ }^{58}$ the importance of age at first birth was clearly demonstrated: the results showed that women with a first birth before they were 18 years old were at $60 \%$ lower risk of breast cancer compared with women with a first birth after the age of 35 years. ${ }^{57,58}$ Subsequent pregnancies seemed to provide only moderate additional protection. Although the association had been described previously, its strength and its importance for understanding the etiology of breast cancer had not been fully appreciated. MacMahon suggested that the long-lasting protection against breast cancer in women with an early first birth may be due to permanent changes in breast tissue caused by the pregnancy. ${ }^{57}$

Research in pathology and cell anatomy was soon providing more direct evidence to support MacMahon's suggestion. Starting in the 1970s, Irma and Jose Russo investigated the development of the mammary gland and susceptibility to carcinogenesis both in humans and in experimental animal models. Their findings indicated that the mammary gland of nulliparous women may be dominated by undifferentiated ductal structures, whereas the breasts of parous women had undergone a differentiation process during 
pregnancy and lactation. They suggested that differentiation of breast tissue is likely to make the breast less vulnerable to cancer development. ${ }^{59}$

However, effects of childbirth had not been exclusively regarded as protective. As Clemmensen pointed out in a commentary:

The higher risk of breast cancer for young married women in comparison with single women at the same age, therefore, seems worth considering. ${ }^{60}$

Many years before, Logan, the chief medical statistician at the General Register Office in London, had studied death rates due to breast cancer in fertile and childless married women based on data from death registration in England and Wales. In 1953, he reported a change in the effect of childbearing on breast cancer mortality after a woman's fertile period. ${ }^{61}$ Compared to childless women, women with children were at higher risk for breast cancer death before the age of 35 years, whereas fertile women $>35$ years of age were at lower risk than childless women. Later, MacMahon et al had also pointed to a possible dual effect of pregnancy: they had found that women with a first birth after the age of 35 years were at higher risk for breast cancer than nulliparous women. ${ }^{57}$ MacMahon's interpretation was that a late first birth may increase the risk of breast cancer through the stimulation of already initiated tumor cells. ${ }^{57}$ In the 1990s, data from MacMahon's international case-control study and two large cohort studies - one Swedish and one Norwegian - confirmed the dual effect of pregnancy, by showing that pregnancy was associated with an increase in short-term risk, followed by a long-term protection and that the increase in short-term risk was higher in women who had their first birth relatively late. ${ }^{62-64}$

The complexity of reproductive factors was captured by Malcom Pike, a statistician and epidemiologist who had worked with Richard Doll. In 1983, he described a model of breast tissue aging, which has been refined later by others. ${ }^{65,66}$ Based on Armitage and Doll's observation that breast cancer is likely to be hormone dependent, Pike concluded that breast tissue ages at different rates during a woman's life. Thus, a constant rate of aging was proposed to start at menarche, followed by a transient increase at first birth, which again is followed by a decrease in the rate of aging. For subsequent full-term pregnancies, this pattern is repeated, but with lower intensity, and at menopause, there is a further reduction in breast tissue aging. The breast tissue aging model made some missing pieces of the puzzle come together and provided a comprehensive model for the role of reproductive factors in the risk of breast cancer.

\section{Conclusion}

It has been a long journey from Ramazzini's reflections of the health of nuns to the current understanding of factors that influence the occurrence of breast cancer. Various scientists from different disciplines have contributed to the knowledge, and the process has not been straightforward; many hypotheses have directed research into unexpected avenues and provided fundamental insights that were previously not regarded plausible. Nonetheless, many unresolved questions remain. A promising approach is the recently established understanding of breast cancer as several distinct molecular subtypes rather than a single disease. ${ }^{67}$ Studying the associations of reproductive and hormonal risk factors according to breast cancer subtype may provide new insight into the development of breast cancer. ${ }^{68}$

\section{Acknowledgment}

Julie Horn was funded by a grant from The Research Council of Norway.

\section{Disclosure}

The authors report no conflicts of interest in this work.

\section{References}

1. Campbell H. A review of studies of breast cancer in human populations excluding endocrine studies. Proc R Soc Med. 1972;65(7): 641-645.

2. Franco G, Franco F. Bernardino Ramazzini: the father of occupational medicine. Am J Public Health. 2001;91(9):1382.

3. Ramazzini B. De Mortis Artificum Diatriba. The Latin Text of 1713, Rev. with Translation and Notes by W. C. Wright. Chicago, IL: University of Chicago Press; 1940.

4. Franco G. Bernardino Ramazzini and women workers' health in the second half of the XVIIth century. J Public Health. 2012;34(2):305-308.

5. Mustacchi P. Ramazzini and Rigoni-Stern on parity and breast cancer. Clinical impression and statistical corroboration. Arch Intern Med. 1961;108:639-642.

6. Rigoni S. Statistical facts about cancers on which Doctor Rigoni-Stern based his contribution to the Surgeons' Subgroup of the IV Congress of the Italian Scientists on 23 September 1842. (translation). Stat Med. 1987;6(8):881-884.

7. Griffiths M. 'Nuns, virgins, and spinsters'. Rigoni-Stern and cervical cancer revisited. Br J Obstetr Gynaecol. 1991;98(8):797-802.

8. Gasparini R, Panatto D. Cervical cancer: from Hippocrates through Rigoni-Stern to zur Hausen. Vaccine. 2009;27(Suppl 1):A4-A5.

9. Fritschi L, Guenel P, Ahrens W; European Study Group on Occupational Causes of Rare Cancers. Breast cancer in priests: follow-up of an observation made 167 years ago. Eur J Epidemiol. 2010;25(3):219-221.

10. Britt K, Short R. The plight of nuns: hazards of nulliparity. Lancet. 2012;379(9834):2322-2323.

11. Fraumeni JF Jr, Lloyd JW, Smith EM, Wagoner JK. Cancer mortality among nuns: role of marital status in etiology of neoplastic disease in women. J Natl Cancer Inst. 1969;42(3):455-468. 
12. Beatson G. On the treatment of inoperable cases of carcinoma of the mamma: suggestions for a new method of treatment, with illustrative cases. Lancet. 1896;148(3802):104-107.

13. Stockwell S. Classics in oncology. George Thomas Beatson, M.D. (1848-1933). CA Cancer J Clin. 1983;33(2):105-121.

14. Tata JR. One hundred years of hormones. EMBO Rep. 2005;6(6): 490-496.

15. Rous P. Leo Loeb (1869-1959). Cancer. 1960;13:437-438.

16. Lathrop AE, Loeb L. Further investigations on the origin of tumors in mice: I. Tumor incidence and tumor age in various strains of mice. J Exp Med. 1915;22(5):646-673.

17. Loeb L. Further investigations on the origin of tumors in mice: VI. Internal secretion as a factor in the origin of tumors. J Med Res. 1919; 40(3):477-496.

18. Sick S. L'œuvre de la Société des Nations dans la lutte internationale contre le cancer de 1923 à 1938. Medicina Storia. 2008:67.

19. Buchanan G. Public action in regard to cancer. Lancet. 1928;212(5474): 160-163.

20. An International Health Organization and the League of Nations. Can Med Assoc J. 1924;14(6):532-533.

21. Departmental Committee on Cancer (Newman G, Bond CJ, Buchanan G, et al). Cancer. Br Med J. 1923;2(3271):421-423.

22. Moscucci O. Gender and cancer in Britain, 1860-1910: the emergence of cancer as a public health concern. Am J Public Health. 2005;95(8): 1312-1321.

23. Eaves L. Local variations in cancer mortality. Boston Med Surg J. 1927;197(21):964-978.

24. Ogilvie M, Harvey J. The Biographical Dictionary of Women in Science: Pioneering Lives from Ancient Times to the Mid-20th Century. New York: Routledge; 2003.

25. Winkelstein W Jr. Vignettes of the history of epidemiology: three firsts by Janet Elizabeth Lane-Claypon. Am J Epidemiol. 2004; 160(2):97-101.

26. Winkelstein W Jr. Janet Elizabeth Lane-Claypon: a forgotten epidemiologic pioneer. Epidemiology. 2006;17(6):705.

27. Lane-Claypon JE. A further report on cancer of the breast with special reference to its associated antecedent conditions. Ministry of Health Reports on Public Health and Medical Subjects No 32; 1926. London.

28. Jasen P. Breast cancer and the language of risk, 1750-1950. Soc Hist Med. 2002;15(1):17-43.

29. Wainwright J. A comparison of conditions associated with breast cancer in Great Britain and America. Am J Cancer. 1931;15(4):2610-2645.

30. Press DJ, Pharoah P. Risk factors for breast cancer: a reanalysis of two case-control studies from 1926 and 1931. Epidemiology. 2010; 21(4):566-572.

31. Greenwood M, Lane-Claypon JE. On the possibility of reducing the rate of mortality from cancer of the breast and cancer of the uterus. Proc Roy Soc Med. 1927;20(5):569-584.

32. Doll R. A conversation with Sir Richard Doll. Epidemiology. 2003;14(3): 375-379.

33. Armitage $P$, Doll R. The age distribution of cancer and a multi-stage theory of carcinogenesis. Br J Cancer. 1954;8(1):1-12.

34. Doll R. Commentary: the age distribution of cancer and a multistage theory of carcinogenesis. Int J Epidemiol. 2004;33(6):1183-1184.

35. Clemmesen J, Busk T. The age distribution of malignant diseases in Denmark 1942-1944. Acta Radiol. 1948;30(1-2):9-16.

36. Herbst AL, Anderson D. Diethylstilbestrol (DES) pregnancy treatment: a promising widely used therapy with unintended adverse consequences. AMA J Ethics. 2015;17(9):865-870.

37. Smith OW. Diethylstilbestrol in the prevention and treatment of complications of pregnancy. Am J Obstetr Gynecol. 1948;56(5):821-834.

38. Junod SW, Marks L. Women's trials: the approval of the first oral contraceptive pill in the United States and Great Britain. J Hist Med Allied Sci. 2002;57(2):117-160.

39. Cogliano V, Grosse Y, Baan R, et al. Carcinogenicity of combined oestrogen-progestagen contraceptives and menopausal treatment. Lancet Oncol. 2005;6(8):552-553.
40. Golditch IM. Lawson Tait: the forgotten gynecologist. Obstetr Gynecol. 2002;99(1):152-156.

41. Lawson Tait R. Diseases of Women. Birmingham: Cornish Brothers; 1886.

42. Wilson RA, Wilson TA. The fate of the nontreated postmenopausal woman: a plea for the maintenance of adequate estrogen from puberty to the grave. J Am Geriatr Soc. 1963;11:347-362.

43. Wilson RA. The roles of estrogen and progesterone in breast and genital cancer. JAMA. 1962;182:327-331.

44. Wilson RA. Feminine Forever. New York: Evans; 1966.

45. Greenberg ER, Barnes AB, Resseguie L, et al. Breast cancer in mothers given diethylstilbestrol in pregnancy. $N$ Engl J Med. 1984;311(22): 1393-1398.

46. Palmer JR, Wise LA, Hatch EE, et al. Prenatal diethylstilbestrol exposure and risk of breast cancer. Cancer Epidemiol Biomarkers Prevent. 2006;15(8):1509-1514.

47. Paffenbarger RS Jr, Fasal E, Simmons ME, Kampert JB. Cancer risk as related to use of oral contraceptives during fertile years. Cancer. 1977;39(4 Suppl):1887-1891.

48. Pike MC, Henderson BE, Casagrande JT, Rosario I, Gray GE. Oral contraceptive use and early abortion as risk factors for breast cancer in young women. Br J Cancer. 1981;43(1):72-76.

49. Breast cancer and hormonal contraceptives: further results. Collaborative Group on Hormonal Factors in Breast Cancer. Contraception. 1996;54(3 Suppl):1S-106S.

50. Ziel HK, Finkle WD. Increased risk of endometrial carcinoma among users of conjugated estrogens. N Engl J Med. 1975;293(23):1167-1170.

51. Design of the Women's Health Initiative clinical trial and observational study. The Women's Health Initiative Study Group. Control Clin Trials. 1998;19(1):61-109.

52. Colditz GA, Hankinson SE, Hunter DJ, et al. The use of estrogens and progestins and the risk of breast cancer in postmenopausal women. N Engl J Med. 1995;332(24):1589-1593.

53. Stanford JL, Weiss NS, Voigt LF, Daling JR, Habel LA, Rossing MA. Combined estrogen and progestin hormone replacement therapy in relation to risk of breast cancer in middle-aged women. JAMA. 1995;274(2):137-142.

54. Rossouw JE, Anderson GL, Prentice RL, et al. Risks and benefits of estrogen plus progestin in healthy postmenopausal women: principal results From the Women's Health Initiative randomized controlled trial. JAMA. 2002;288(3):321-333.

55. Cole P. Proceedings: epidemiology of human breast cancer. J Invest Dermatol. 1974;63(1):133-137.

56. MacMahon B, Lin TM, Lowe CR, et al. Lactation and cancer of the breast. A summary of an international study. Bull World Health Organ. 1970;42(2):185-194.

57. MacMahon B, Cole P, Lin TM, et al. Age at first birth and breast cancer risk. Bull World Health Organ. 1970;43(2):209-221.

58. MacMahon B. A conversation with Brian MacMahon. Interview by Walter Willett. Epidemiology. 2004;15(4):504-508.

59. Russo J, Moral R, Balogh GA, Mailo D, Russo IH. The protective role of pregnancy in breast cancer. Breast Cancer Res. 2005;7(3):131-142.

60. Clemmensen J. Breast cancer and reproduction. Lancet. 1970; 2(7679):928.

61. Logan WP. Marriage and childbearing in relation to cancer of the breast and uterus. Lancet. 1953;265(6797):1199-1202.

62. Hsieh C, Pavia M, Lambe M, et al. Dual effect of parity on breast cancer risk. Eur J Cancer. 1994;30A(7):969-973.

63. Lambe M, Hsieh C, Trichopoulos D, Ekbom A, Pavia M, Adami HO. Transient increase in the risk of breast cancer after giving birth. $N E n g l$ J Med. 1994;331(1):5-9.

64. Albrektsen G, Heuch I, Kvale G. The short-term and long-term effect of a pregnancy on breast cancer risk: a prospective study of 802,457 parous Norwegian women. Br J Cancer. 1995;72(2):480-484.

65. Pike MC, Krailo MD, Henderson BE, Casagrande JT, Hoel DG. 'Hormonal' risk factors, 'breast tissue age' and the age-incidence of breast cancer. Nature. 1983;303(5920):767-770. 
66. Rosner B, Colditz GA. Nurses' health study: log-incidence mathematical model of breast cancer incidence. J Natl Cancer Inst. 1996; 88(6):359-364.

67. Sorlie T, Perou CM, Tibshirani R, et al. Gene expression patterns of breast carcinomas distinguish tumor subclasses with clinical implications. Proc Natl Acad Sci U S A. 2001;98(19):10869-10874.
68. Sisti JS, Collins LC, Beck AH, Tamimi RM, Rosner BA, Eliassen AH. Reproductive risk factors in relation to molecular subtypes of breast cancer: results from the nurses' health studies. Int J Cancer J. 2016; 138(10):2346-2356.

International Journal of Women's Health

Dovepress

\section{Publish your work in this journal}

The International Journal of Women's Health is an international, peerreviewed open-access journal publishing original research, reports, editorials, reviews and commentaries on all aspects of women's healthcare including gynecology, obstetrics, and breast cancer. The manuscript management system is completely online and includes

a very quick and fair peer-review system, which is all easy to use. Visit http://www.dovepress.com/testimonials.php to read real quotes from published authors.

\footnotetext{
Submit your manuscript here: http://www.dovepress.com/international-journal-of-womens-health-journal
} 